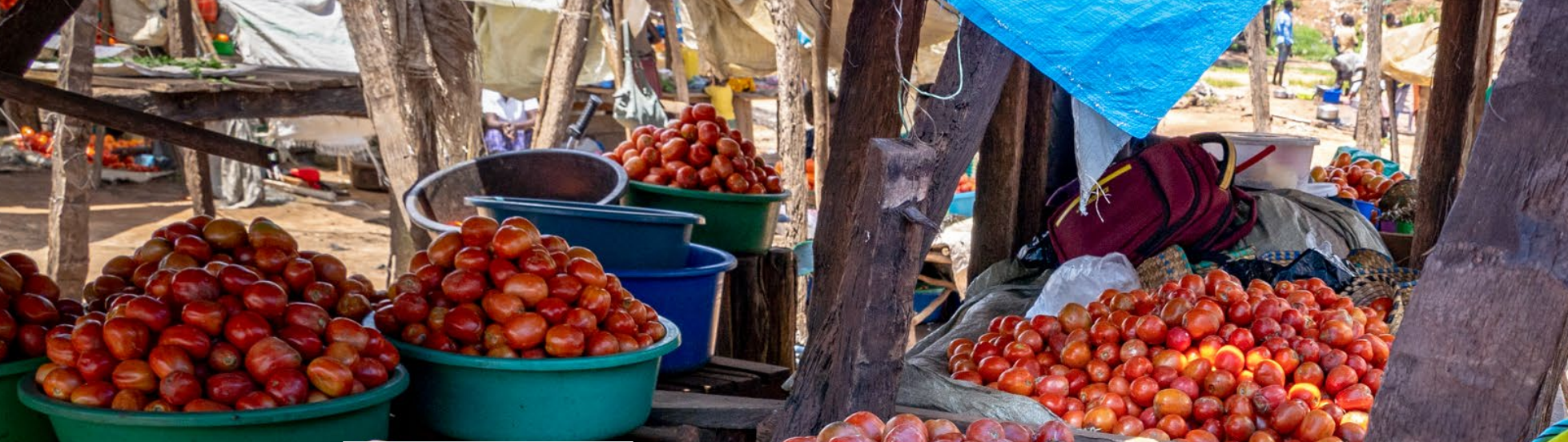

\title{
Inclusive Agricultural Trade Scan
}

Joost Guijt, Jan Willem Molenaar and Monika Sopov 


\section{Table of contents}

Concepts Inclusive agribusiness Concepts Inclusive value chains Concepts Inclusive environment Inclusive Trade Scan Step 1 Target groups Step 2 Engagement Step 3 Impact Step 4 Context Step 5 Priorities
Introduction

Part 1. Understanding the concepts

Understanding Inclusiveness

Three levels of trade:
a. Inclusive agribusiness
b. Inclusive value chains
c. Inclusive trade environment

Part 2. The inclusive trade scan

Step 1, Initiative and target groups

Step 2, Engagement

Step 3, Impact

Step 4, Context

Step 5, Priorities

What's next

Relevant tools and resources

Colophon

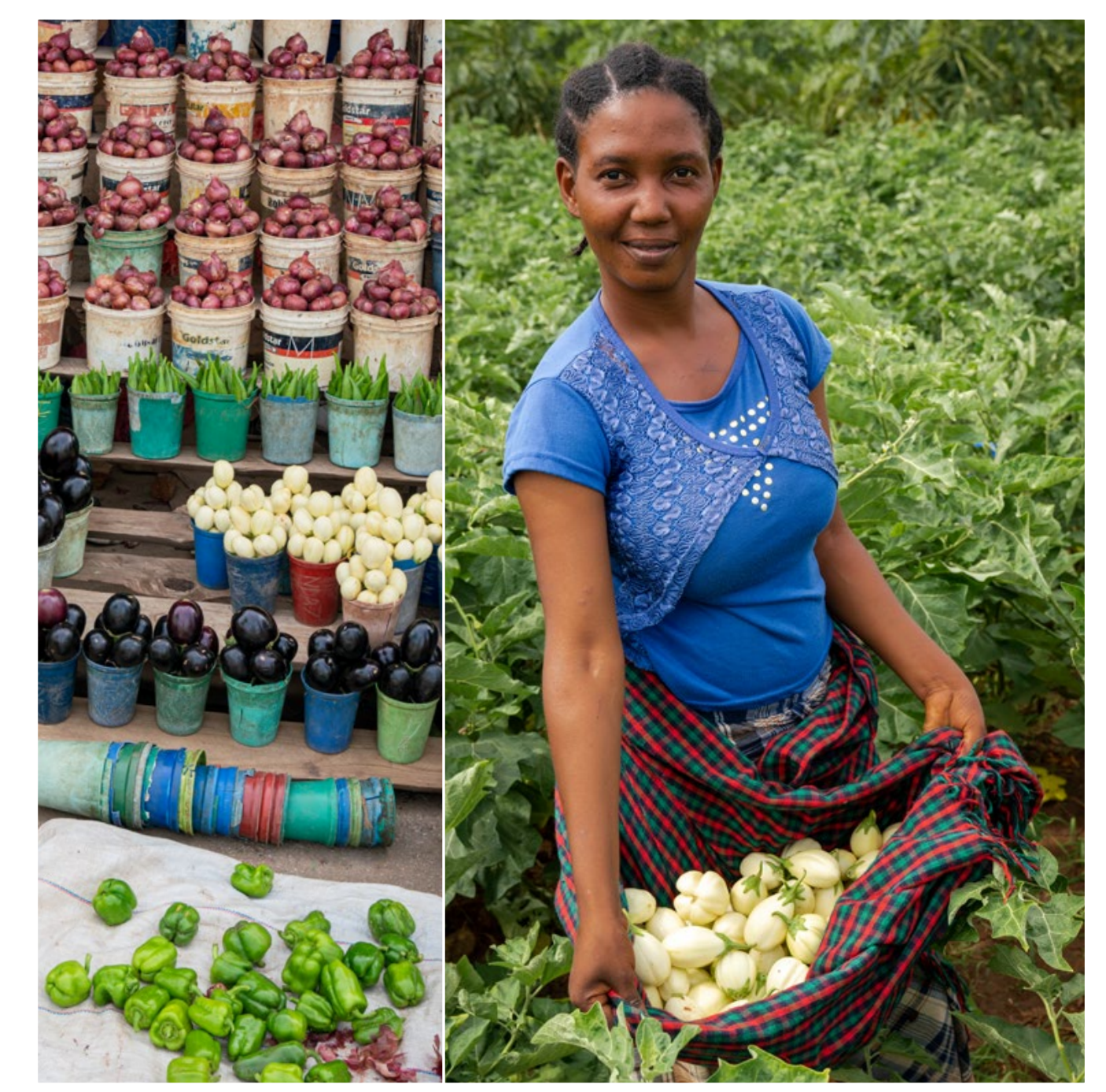

Eggplant grown for the local market in Tanzania provides picking jobs and fresh products
3 4 4 


\section{Understanding inclusiveness}

There are many descriptions and definitions of inclusive agribusiness; the exact definition is not critical. What is important is to think about what inclusive agribusiness aims to do: to structurally improve the opportunities and benefits of agribusiness relationships for low-income and disempowered people. Opportunities and benefits can be improved on the supply side (as a producer or employee) and on the demand side (as a consumer).

While often emphasis is placed on the benefits to livelihood (i.e., economic benefits), social and environmental benefits can also be targeted. Finally, inclusive agribusiness and trade is deliberate about enhancing inclusivity in the design and implementation of initiatives.

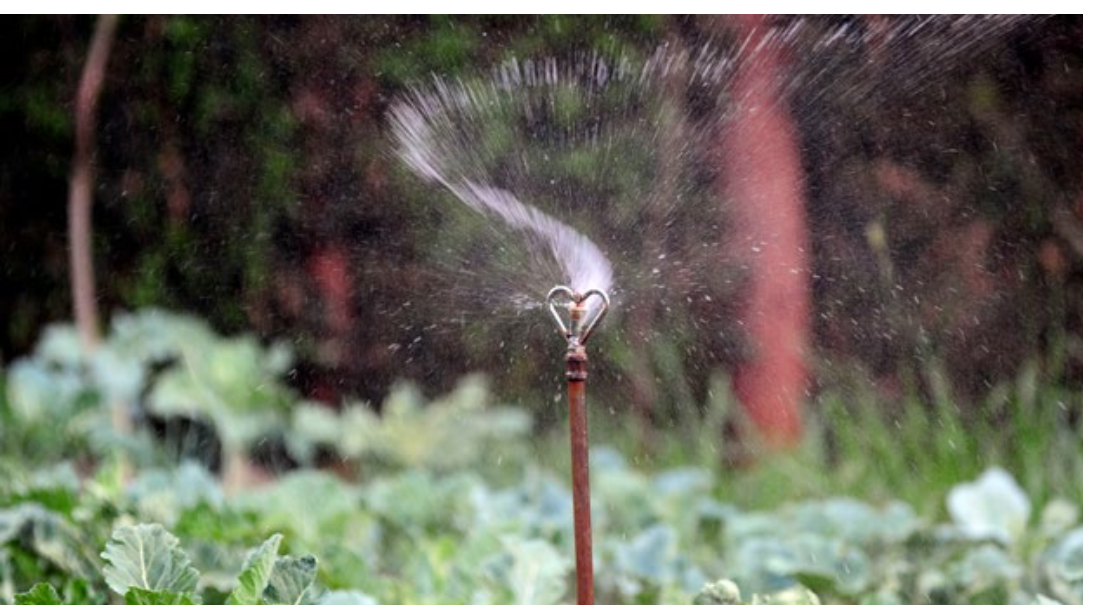

Vegetable irrigation
In this tool, we identify three aspects of inclusiveness:

1. Who is included: the social groups that are typically excluded from exerting power over, and receiving major benefits from, agribusiness relationships, and who are now deliberately being drawn in. These typically include smallholders, women, elderly, youths, the landless, the jobless, minorities, and so on. Since the inclusion of a particular group is deliberately targeted, we refer to these as the 'target groups' of the inclusive initiative.

2. How are they included: the process by which the target groups are involved in the design, implementation, and outcomes of the inclusive initiatives.

3. What the effect is: the intended outcomes for the target groups, whether economic, social, or environmental. This tool is meant to help the user assess the inclusiveness of an initiative, project intervention, or investment. In the rest of this document, any of these four terms is used to refer to all the others.

In the tool, we make a distinction between "engagement" and "impact" in relation to inclusivity. Engagement is about who and how, while the impact is about what.

\section{Engagement: WHO and HOW}

Being more inclusive begin with the process of tackling a new initiative. This includes who is checking whether things are being done appropriately and properly (due diligence), the way different target groups are consulted or take part in decision-making processes (the principles of engagement), how problems and issues can be addressed (remediation), how progress is monitored and communicated (accountability).

The following aspects strongly affect the shape taken by a new initiative.

- identifying who you want to benefit from the business initiative.

- assessing their needs.

- engaging them in decision-making

- providing space for remedies.

- monitoring the outcomes of the project as input for adaptive management.

\section{Impact: WHAT}

The outcomes refer to the opportunities and benefits for all groups involved in the initiative - and in particular for the target groups that are in need of greater inclusivity. These outcomes can be considered in terms of the following well-known dimensions.

- Relevance: is the initiative relevant to your target groups?

- Effectiveness: does the initiative contribute to more fairness and improved economic, social, and environmental opportunities and benefits for your target groups?

- Continuity: can the initiative and its impact be sustained over time?

- Scale: does the initiative create opportunities that are scalable across all target groups? 


\section{Understanding inclusiveness}

Key outcomes of inclusive trade are:

Concepts

Inclusive agribusiness

Concepts

Inclusive value chains Concepts

Concepts
Inclusive environment

Inclusive Trade Scan Step 1 Target groups Step 2 Engagement Step 3 Impact Step 4 Context Step 5 Priorities

\section{1.}

Vulnerable groups are included in diverse parts of the value chain, based on strong value propositions.

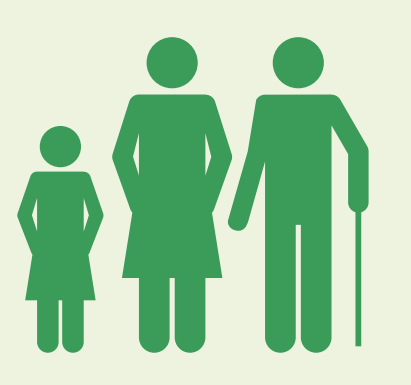

\section{2.}

Products and services are provided that are agreeable, affordable, safe and healthy, sustainable and accessible to all.

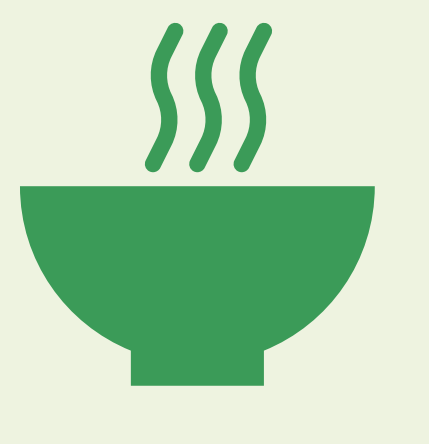

\section{3.}

Business generates profits that through fair taxation and/or corporate programs also contribute public goods.

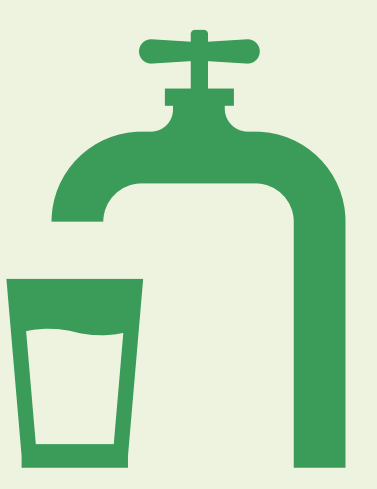

4.

Stewardship of the natural resource base becomes a shared responsibility.

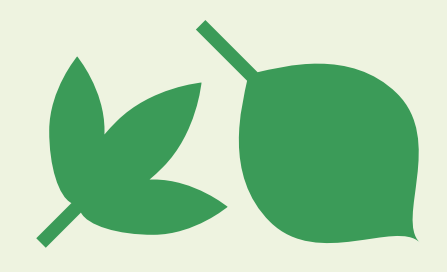

\section{5.}

Responsible agribusiness investments \& inclusive business models can demonstrate contribution to the Sustainable Development Goals (SDGs).

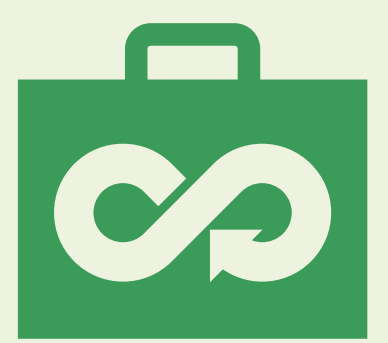




\section{Three levels of initiatives}

Inititatives related to agricultural production and trade can be divided into three levels: individual agribusinesses, value chains and the trade environment. Each has its own dimensions relevant to greater or lesser inclusivity. Greater inclusion ultimately needs to take place for the individual person who is connected to an agribusiness level. The value chain and trade environment need to ensure that greater inclusion takes place where it is needed.

\section{A. Inclusive agribusiness}

Inclusive agribusiness initiatives usually look at how an individual company creates opportunities and benefits for low-income and disempowered groups "such as smallholders and surrounding communities". These initiatives are usually run by individual agribusinesses that are close to these groups "such as large-scale producers, primary processors, and traders with direct links to smallholders". Agribusiness initiatives can also look at the workers they employ or the consumers they try to reach.

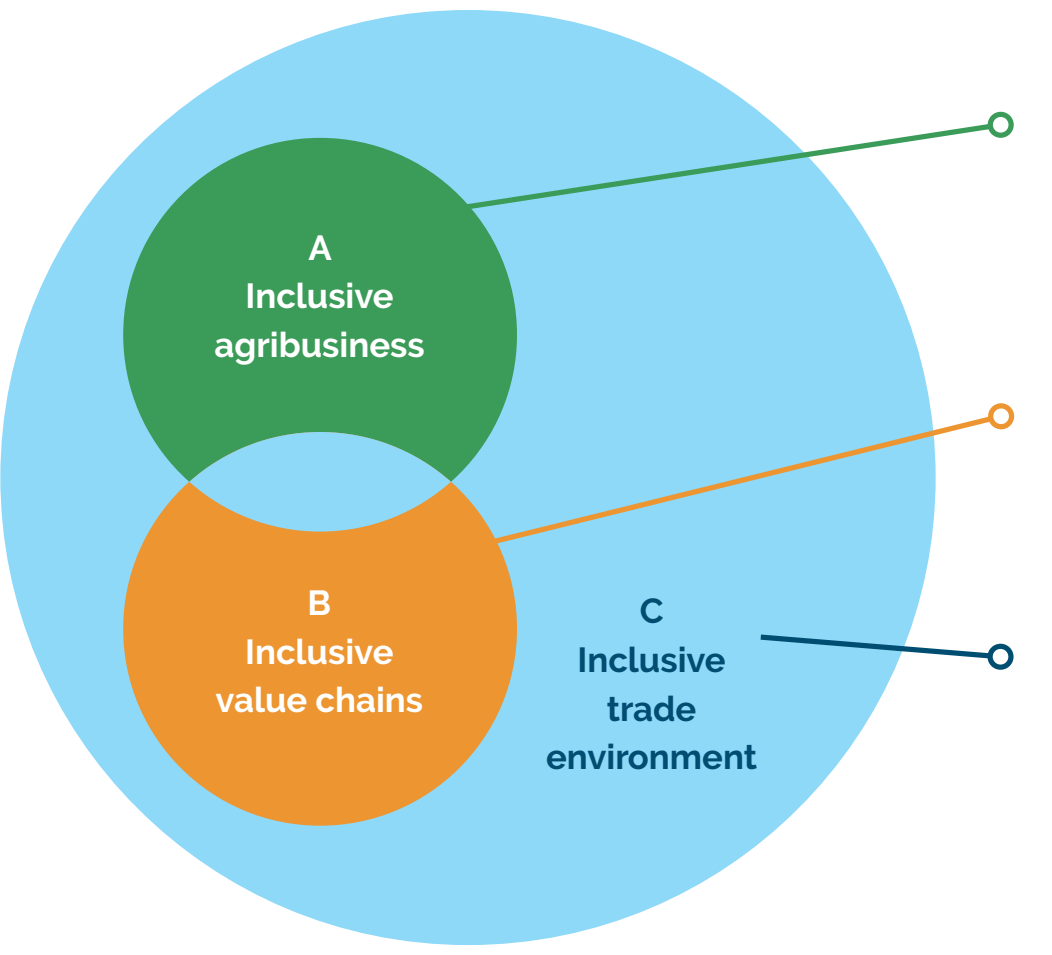

A. Initiatives by a company active in the production, transport and/or processing of agricultural products. (Key components: relationships with workers, suppliers and consumers.)

B. Trade related initiatives of companies operating downstream of an agricultural value chain. (Key components: trading relationships, value creation, and distribution.)

C. Initiatives related to the institutional and regulatory environment, or the services available to agribusinesses or value chain actors to support their investments in inclusiveness. (Key components: institutions, regulation and support services.)

\section{B. Inclusive value chains}

The space an individual agribusiness has to invest in inclusiveness depends partly on its terms of trade with its immediate buyers. These terms may depend on the terms set further downstream the value chain. For example, unfair trading conditions, such as low prices, late payments, or a lack of respect for contracts can undermine an agribusiness' investments in inclusiveness. By contrast, fair trading practices, such as long-term purchasing agreements, fair prices, or prefinance can all facilitate such investments. Inclusive agribusiness thus requires inclusive value chains.

\section{Inclusive trade environment}

The performance of agribusinesses and value chains depends partly on the enabling environment, which refers to how sectors are governed. This includes policies and regulations (such as trade, labour rights, and land tenure), planning and coordination, and public investments made in a sector. The enabling environment also refers to the services available to agribusinesses and other value chain actors. Services that can support investments in inclusiveness include research, finance, technology transfer, input provision, and the dissemination of market information 


\section{Inclusive agribusiness}

Inclusive agribusiness initiatives create opportunities and benefits for low-income and disempowered groups. The groups can consist of workers, suppliers, communities, or consumers.

Inclusive agribusiness initiatives should not be about isolated or temporary projects. An inclusive agribusiness makes inclusiveness an integral part of its business model. This requires leadership buy-in and supportive corporate policies and tools, as well as performance measurement and reporting on relevant topics.
The following topics could be relevant when promoting inclusive agribusiness:

\section{Worker relationships}

- Staff composition, such as gender balance, hiring of local people, and hiring of disabled people.

- Working conditions, such as wages, health and safety measures, maternity leave, health insurance, and working hours.

Supplier relationships

- Local procurement of products and services, such as from smallholders, women, and local businesses.

- Procurement practices, such as long-term purchase commitments, sourcing plans, short payment terms, no bonded contracts, and prefinance.

- Service delivery, such as the provision of inputs, capacity building, and finance to suppliers.

Community relationships

- Respect for ownership and user rights to land and other natural resources, such as water and forests.

- Avoiding pollution and disturbances, such as waste, noise, and air pollution.

- Community engagement and investment, such as investment in water and sanitation, education and health services; sponsorship of local sports and cultural associations; promotion of alternative income-generating activities for women and youths, complaint mediation, such as in case of conflict or breaking contract.
Consumer relationships

- Creating products and services that are demanded by your target groups; drawing target groups in during product development.

- Ensuring products and services are accessible and affordable, such as through package sizes and distribution networks.

Inspiration from: UN Guiding Principles Reporting Framework $\&$ Blab Best Practice Guide: Diversity \& Inclusion in Your Workplace

Do the Inclusive Trade Scan and assess the inclusiveness of projects, initiatives, and/or investments relating to inclusive agribusiness. 


\section{Inclusive agribusiness}

\section{Case example}

\section{Guts Agro Industry, Ethiopia}

Guts Agro Industry is an ISO 22000-2005 certified company that processes nutritious foods, it is headquartered in Bishoftu (also called Debrezeit) in Ethiopia. It was established in 2005, and by 2017 it had 160 employees and had quadrupled its capital. Since its establishment, Guts Agro Industry has introduced innovative products that meet the highest nutritional standards at affordable prices. Guts Agro offers super cereal (CSB+), Lembo snacks, Yanetshiro powders, MAmole iodized table salt, and purified industrial salts to the local market. It has developed baby cereals marketed under the Libdel brand, as well as a high-quality.

low-cost nutritious food branded "Supermom's",

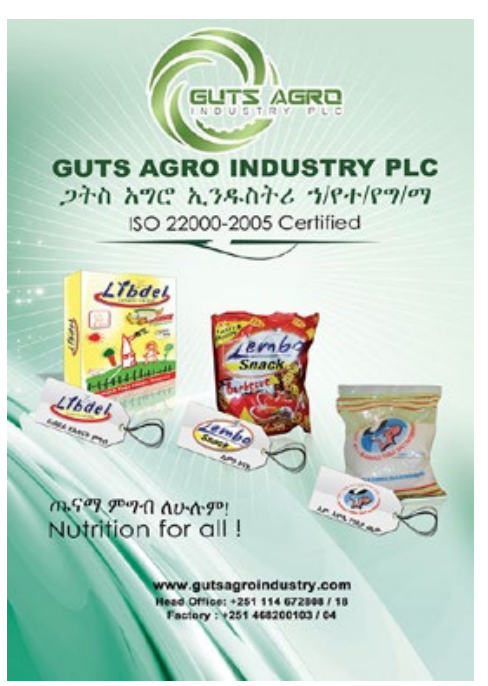

Supplier relationships

While trying to ensure that its supply is sustainable, the company's operations have benefited several thousand local farmers, creating sustainable markets for their produce via their respective cooperative unions.

"Working with cooperatives is not easy. But we still believe that it is the best option. We have a responsibility towards the local people, the beneficiaries of our operations, and for sustainability and traceability. These people are close to our factory; they should be aware of the benefit of their produce, what can be made from their maize."
Worker relationship \& gender

The company introduced the first door-to-door distribution model in the country, with the aim of reaching low-income consumers with all its affordable products. The distribution model is known by the brand name LIKIE, Amharic for means 'my size' or 'tailored for me'. It operates in four regions: Oromia, Amhara, SNNPR, and Dire Dawa.

All the nutritious food the company makes is handled by women. To distribute its products, Guts Agro works with 120 entrepreneurial

female agents. They chose middleaged women who were married with two to four children, who might breastfeed her children.
Community relationship

Engidu Legesse Yesuneh, cofounder of Guts Agro explains:

"We also try to use the local language for brands we develop, such as Lembo Snacks. The locals love it when they realize that it is made of maize. This changes the industry. The farmers changed us as a company. They changed our workers, and indirectly our suppliers, our packaging, and the country as whole."

As part of its corporate social responsibility, the company supports 40 orphans in Hawassa city in collaboration with the Mary Joy Development Association, and provides potable underground water for the local communities around its Bishoftu compound. 


\section{Case example}

Tony Chocolonely

Stories of children working as slaves on cocoa plantations in West Africa formed the basis for the foundation of Amsterdam-based chocolate company Tony's Chocolonely. In 2003, a group of Dutch investigative journalists discovered this type of slavery. Flabbergasted, they tried everything they could think of to tell the world about the problem and the need to fix it. After numerous disappointments, they decided to set an example by trying to produce a slave-free chocolate bar themselves. Almost fifteen years later, this journalism project has evolved into the leading chocolate producer in the Netherlands: Tony's Chocolonely.

TONY'S YALUE (BLOGK) GHAIN

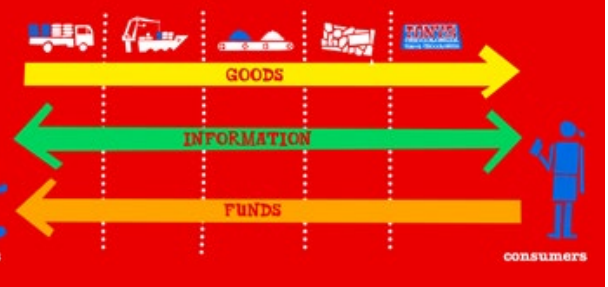

Henk Jan Beltman, one of three owners, sees Tony's as a social enterprise, even though, in his vision, social entrepreneurship is a label that will hopefully no longer be necessary in the near future. 'If you say "we're a for-profit company", you're mixing up your goal and your means. Social entrepreneurship implies by definition that you balance your striving for social goals with entrepreneurship. The mission always comes first. Tony's aim is to create the conditions for the eradication of child slave labour, ultimately aiming to positively alter the practices of the bigger chocolate companies in the world. Tony's thus states that 'together, we want to make chocolate $100 \%$ slave-free.

Trading relationships and value creation

\section{Transparant supply chains}

Most chocolate brands currently

buy their beans on the bulk market where beans cannot be traced back. Tony's wants to take responsibility for its entire value chain, and thus ensures its chocolate is $100 \%$ traceable. To put these ideas into practice, the company is developing a system called Beantracker. This system makes it possible to trace Tony's beans by following the location and quantity of beans in real time. Tony's believes that cooperation is vital to ban slavery and child labour. For this reason, the Beantracker system will also be made available to Tony's competitors.

\section{Fair pricing}

The price farmers receive for their cocoa beans is generally too low to provide farmers with a living income-an amount with which they can meet their basic needs. The farmers receive a 'farm-gate price' for each kilo; this is a minimum price set by the governments of Ghana and Ivory Coast that is tied to the market price. To ensure a living income, Tony's pays two additional premiums: a Fairtrade premium and the Tony's premium. The Fairtrade premium is set at USD 200 per ton and is paid to the local trader by Tony's export partner CocoaSource. Tony's additional premium, which has been paid out since 2013, is determined on a seasonal basis by looking into new insights about living incomes and up-to-date farmgate prices. At the time of writing the farm-gate price is at an all-time low. Tony's premium is therefore USD 400 per ton. This premium is paid out to the farmers' cooperatives.

Stable trading relationships One of the ways in which Tony's is trying to halt slavery and child labour is by investing in long-term commitments, at least five years in duration, with cooperatives in Ivory Coast and Ghana and other partners in the value chain. This provides cooperatives and farmers with income certainty, enabling them to invest in better technologies for future production

\section{Strengthening the position} of farmers

When farmers join forces in cooperatives, they can share knowledge, search for new buyers and markets, and access resources cheaper by using the advantage of scale. Despite these benefits, only $30 \%$ of farmers in West Africa are members of a cooperative. Tony's wants to show farmers the benefits of joining a cooperative, and therefore invests in the professionalization of their partner cooperatives.

\section{Service delivery}

In its Annual Fair Report 2016-2017. Tony's clearly states that "it is also the farmers' responsibility to maximize their income. They have to run their farms professionally so they produce at least $800 \mathrm{~kg}$ per hectare. In practice, many farmers do not manage this production rate, and have an average production rate of approximately $450-500 \mathrm{~kg}$ per hectare. In these cases, even with the premium, farmers will not earn a living income."

For this reason, Tony's also supports the professionalization of farmers by providing financial resources and connecting farmers with local consultants. They work with 'role model farmers', who inspire and empower others to use innovative techniques 


\section{Inclusive trade environment}

The performance of agribusinesses and value chains partly depends on the enabling environment, or trade environment. In fact, once an inclusive business is established and is operating with inclusive values, the trade environment becomes a major influence on the possibility for this greater inclusiveness to become the 'new normal way of doing business'.

The enabling trade environment has two basic components: institutions and regulations and support services.

\author{
Institutions and regulations
}

The public (or semi-public) institutions, the formal and informal decision-making processes, policies and regulations form an important part of the inclusive trade environment. It is important to consider how they increase or reduce opportunities and benefits for low-income and disadvantaged people. To enable inclusive agricultural production and trade, they should support the creation of a level playing field, regulatory and financial incentives for inclusiveness, alignment between key stakeholders, and strategic investments. The following functions can be considered in this component:

- Stakeholder dialogue and coordination: The creation of sector platforms or governing bodies to align key stakeholders around a shared vision and a road map for the sector, develop common standards, guidelines, and tools, influence public and private policies and promote of sector-wide monitoring and learning.

- Policy and regulation: The establishment of coherent rules and systems that effectively govern sectors. Key elements include market management (such as regulations related to trade, quality, price, demand, and supply), social and environmental regulation (such as labour, water, and forests), land governance (for example, land use planning and land tenure), and the rules governing producer organizations (such as cooperative law) and service provision (licenses and imports, for example).

- Investment: The generation of revenues on the sector level to make strategic reinvestments in for example, research, quality management, or market promotion. Key elements include revenue generation mechanisms (such as taxes and fees) and reinvestment mechanisms (like subsidies, trust funds, investments, and loans).

\section{Support services}

The second component of the enabling trade environment is the services available to agribusinesses and value chain actors to support their investments in inclusiveness. It is important to promote those services and delivery models that are tailored to needs of specific segments of these actors and to the ultimate target groups. Such services may include:

- Research and development, for example in better-performing crop varieties, inputs, and crop management systems, processing, packaging, and transportation.

- Infrastructure, such as transport, communication, energy, market, water, sanitation, education, and healthcare.

- Information, such as market information and weather services.

- Capacity building, such as training, demonstrations, monitoring, and knowledge tools.

- Inputs and technology, for example, plant material, fertilizers, machinery, and packaging material.

- Financial services, like short, medium, and longterm credit, insurance, and hedging.

- Market promotion, such as branding and marketing of national products, trade missions, and exhibitions.

Inspiration from Springfield, Aidenvironment, CFS Principles for Responsible investment in agriculture and food systems, $3 R$ Issue Brief

Do the Inclusive Trade Scan and assess the inclusiveness of projects, initiatives, and/or investments relating to inclusive agribusiness. 


\section{Inclusive trade environment}

\section{Case example}

\section{The Philippines: Pioneering inclusive business policy}

Inclusive business is needed to provide solutions to the poor: in the Philippines, about $60 \%$ of the population (or 57 million people) have a family income of less than PHP 18,000 a month ( $\$ 3$ per head per day), $40 \%$ have less than PHP 12,000 (about $\$ 2$ a day), and $26 \%$ live in absolute poverty with less than PHP 8,500. To tackle this high level of poverty and to address some of the related development challenges, the government of the Philippines has identified the promotion of inclusive business as a key policy priority.

An ADB study in 2013 estimated that there are about 20,000 social enterprises, cooperatives, NGOs and community-based organizations in the Philippines all working in one way or the other with the poor. However, the poverty rate has not declined in a decade. The study found that there are perhaps only 100 inclusive business models, of which as few as 15 are investable. The government has thus decided to take a more radical approach to the promotion and development of inclusive business.

\section{Sector governance}

\section{Investment}

The most pioneering step has been the development of an Inclusive Business Accreditation System that helps to distinguish inclusive business models from other types of investment. This has been put in place for three key reasons:

1. Accreditation systems are important in establishing trust and accountability for new concepts - as shown, for example, in the fair trade, sustainability, and organic market sector.

2. While all companies contribute to economic growth, only a few companies have business models that make growth more inclusive.

3. For government programs and banks to better target investment support, there is a need to distinguish companies generally contributing to growth from companies with inclusive business models.

Some of the recommendation related to IB-accredited companies:

1. There should be a Services and Monitoring Lane established for inclusive business-accredited projects: such projects that are also registering for incentives should be prioritized to receive advisory services for dealing with other government agencies in the paper trail, as well as aftersales service in complying with registration and accreditation requirements.

2. Lending institutions financing accredited agribusiness and tourism projects should qualify for enhanced guarantee cover.

3. Inclusive businesses can be further enhanced by granting preferential treatment to base-of-pyramid households linked with inclusive businesses and their enterprises. Such support may be designed so as to prioritize MSMEs already linked to inclusive businesses. Moreover, an inclusive business may be tasked with providing technical and other services, so as to optimize government support for MSMEs.

Fiscal incentives: Inclusive Business Policy Plus

A more radical approach to integrating inclusive business in government programs entails major legislative changes in fiscal incentives, mandatory allocation, and subsidies. For fiscal incentives, reforms are divided into two scenarios.
1. Inclusive business-accredited projects should qualify for pioneer status in the fiscal incentive scheme. For domestic firms, pioneer status extends the ITH by two years; for foreign investors, pioneer status entitles them to register with the BOI for both fiscal and nonfiscal incentives (subject to other conditions, such as exporting $70 \%$ of its production and divesting to

Filipino ownership after 30 years.)

2. Under a new fiscal incentive regime, grants of fiscal incentives should be reserved exclusively for firms with inclusive business accreditation.

3. To promote inclusive business and social impact, base-of-pyramid households and suppliers within an inclusive business-accredited value chain should be prioritized to receive transfers. Capital financing for MSMEs should be provided using matching grants for enterprise development; capital financing for socialized housing should be provided as copayment grants to base-of-pyramid households. 


\section{Part 2: Inclusive Trade Scan}

The purpose of the Inclusive Trade Scan

To support companies, governments, development agents and donors to:

- Reflect on the inclusiveness of a particular

initiative in a structure manner.

- Facilitate an informed dialogue on how initiatives can become more inclusive.

\section{Inclusiveness in agriculture}

Inclusiveness refers to how initiatives engage with low-income and disempowered people and deliberately create economic, social, or environmental benefits to them.

\section{Three levels of initiatives}

An initiative can refer to a project, investment, business, policy, etc. The tool applies to the following levels of initiatives:

- Individual agribusiness: initiatives by a company active in the production, transport and/or processing of agricultural products.

- Agricultural value chains: trade related initiatives of companies operating downstream of an agricultural value chain.

- Trade environment: initiatives which concern the institutional and regulatory environment or the services available to agribusinesses or value chain actors to support their investments in inclusiveness.

\section{When to use the scan?}

The Inclusive Trace Scan can be applied at any moment in the lifecycle of an initiative.

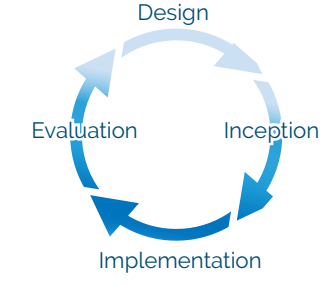

It helps to:

- Identify target groups and reflect on how you want to take them into consideration.

- Communicate expectations and performance on inclusiveness.

- Identify actions to enhance inclusiveness, including what to target in the enabling environment.

- Monitor changes in inclusiveness over time.

\section{Who should fill it in?}

The scan can be filled in by a single person, but it is recommended that multiple people use it to promote verification and interactive reflection. These can be people from within the same organization or from partner organizations. Comparing answers and discussing differences for the same initiative can be an effective way of gaining understanding of the current situation, and of where greater inclusion might be possible.

\section{How long does it take?}

Filling in the Inclusive Trade Scan can take less than an hour for an individual. It is recommended to spend more time on discussing the answers and priority actions among colleagues or partners.

\section{Structure of tool}

Step 1, Initiative and target groups: Who do you want to include? Describe your initiative and its target groups

Step 2, Engagement: How do you engage with your target groups? Answer questions that will help you reflect on how you engage with your target groups.

Step 3, Impact: How are target groups affected by your initiative? Answer questions to reflect on how your initiative (will) affect your target groups.

Step 4, Context: How does the context influence your inclusiveness? Describe the context of the initiative following the three business levels described previously: individual agribusiness, value chain, and trade environment

Step 5, Priorities: What solutions are needed? Set your priorities for action for greater inclusion.

What's next?

Identify actions to give follow-up to this exercise 


\section{Step 1, Initiative and target groups: who do you want to include?}

\section{A. Initiative}

Please describe briefly the objectives, key activities and partners in the initiative.

Whether you are an agribusiness, value chain actor or an organization working on the trade environment, the Inclusive Trade Scan starts with a description of the initiative to which you want to apply the scan. An initiative can be a project, strategy or investment (e.g the introduction of a new product, service or technology. a workers' policy, sourcing program or marketing campaign). It can also refer to an entire cooperative, company, business unit or value chain relationships. The scan can also be used for a public policy, regulation, or stakeholder dialogue mechanism.

For an agribusiness initiative: Describe your business in terms of what products or services you are creating, who your market is, what market demand you are meeting. how you get your products to your customers.

\section{B. Target groups}

\section{Please describe the low-income and disempowered} target groups which your initiative is affecting or can potentially affect.

One can think of:

- small-scale producers

- neighboring communities

- workers

- consumers

Where relevant, differentiate target groups by income, gender, age, farm-size, ethnicity, etc.
Add who your suppliers are and what they supply, who your workers are and in what communities you operate.

For a value chain initiative: Describe the products you source and/or sell, key business partners, both upstream and downstream, and what you offer each other in terms of goods and services. Describe key aspects of your trading relationship: how you communicate, key terms of trade, how terms of trade are decided on. Also describe how you create value together and how that is shared between you.

For a trade environment initiative. Describe the institutional and regulatory issues you try to address and the sectors and actors they apply to. Or describe the type of supportive services you try to develop and improve, the pricing and delivery mechanisms.

Note that in cases where it is difficult to combine findings across target groups, it is recommended to repeat the Inclusive Trade Scan for each target group. For example the outcomes of the Scan may be very different when considering the small-scale producers you source from. the workers that work in your factory or the consumers you target. Similarly, regulatory initiatives can have very different outcomes for different type of producers or regions. In those cases, apply the tool separately for each target group.
A. Initiative

B. Target groups 


\section{Inclusive Trade Scan}

\section{Step 2, Engagement: How do you engage with your target groups?}

\section{An important aspect of inclusiveness is how} you engage with your target groups. This

\section{includes:}

- the way different target groups are

consulted or take part in decision-making processes (the principles of engagement) - who is checking whether things are being done appropriately and properly (due diligence);

- how problems and issues can be addressed (remediation);

- how progress is monitored and

communicated (accountability).

The questions in step 3 have four answer options. They are:

- Never: you do not do this at all

- Sometimes: you do this occasionally

- Regularly: you do this regularly, but not always for everyone or thoroughly

- Always: you do this always, for everyone and thoroughly

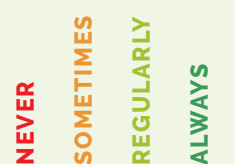

1. Are you identifying low-income and disadvantaged groups (i.e., the target group) that are potentially affected by your initiative?

Considerations: Think about those target groups you defined in step 1 that could be directly or indirectly affected by what you are doing and how you arrange that.

2. Are you assessing at an early stage how the initiative will affect the target group positively or negatively?

Considerations: This can be within your team only, within your business, through consultation with your target group or by asking civil society groups.

3. Are you engaging the target group in decision-making processes regarding the initiative?

Considerations: Think about who decides about things ranging from what products/services you are offering, how trade relationships are set, how and when you communicate about what, etc

\section{Notes}

Notes 


\section{(2) Inclusive Trade Scan}

\section{Step 2, Engagement: How do you engage with your target groups?}

\section{An important aspect of inclusiveness is how} you engage with your target groups. This

includes:

- the way different target groups are

consulted or take part in decision-making processes (the principles of engagement) - who is checking whether things are being done appropriately and properly (due diligence);

- how problems and issues can be addressed (remediation);

- how progress is monitored and

communicated (accountability).

The questions in step 3 have four answer options. They are:

- Never: you do not do this at all

- Sometimes: you do this occasionally

- Regularly: you do this regularly, but not always for everyone or thoroughly

- Always: you do this always, for everyone and thoroughly
4. Are you remedying the situation if your

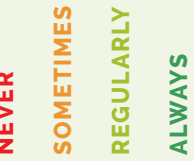
target group is harmed by actions or decisions related to your initiative?

Considerations: Think about any complaints procedures you have in place, or how you follow up on internal progress meetings that flag negative effects.

5. Are you monitoring the impact of your action on target groups, share these insights and adapting what you are doing where needed?

Considerations: Think about any indicators you may have that are relevant to some aspect of inclusiveness described earlier, and how you use them in the way you monitor progress.
Notes

Notes 


\section{Step 3, Impact: How are target groups affected by your initiative?}

\section{Impacts refer to the opportunities and}

benefits for all groups involved in the

initiative - and in particular for the

target groups that are in need of greater

inclusivity. The impacts can be considered

in terms of the following well-known

dimensions:

- Relevance: is the initiative relevant to your target groups?

- Effectiveness: does the initiative cotribute

to more fairness and improved economic.

social, and environmental opportunities and

benefits for your target groups?

- Continuity: can the initiative and its impact be sustained over time?

- Scale: does the initiative create

opportunities that are scalable across all

target groups?

The questions in step 4 have four answer options. They are:

- No: this is not the case/we do not know

- Limited: this can happen occasionally / of rather poor quality

- Substantial: this is generally the case, but not always or as good as we would like to

- Yes: this is happening at the desired level

\section{Relevance}

Does the initiative...

Create opportunities and benefits that

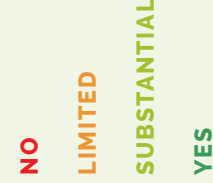

$\square \square \square \square-\quad$ Notes

\section{meet the different needs of specific}

target groups?

Considerations: Is your initiative doing the right things for your target group? Does it respond to their needs and priorities? Does it consider trade-offs between different priorities or needs?

2. Ensure target groups have the

Notes awareness and capabilities needed to

capture the opportunities?

Considerations: Are you investing in any kind of capacity development for your target group: trainings, demo's, skills classes, etc?

3. Have the flexibility to adapt to changing context and needs?

Considerations: Do you have an regular product assessment and adaptation process? Do you have regular reflection moments/ processes to remain relevant for target groups? 


\section{Step 3, Impact: How are target groups affected by your initiative?}

Impacts refer to the opportunities and benefits for all groups involved in the

initiative - and in particular for the

target groups that are in need of greater

inclusivity. The impacts can be considered

in terms of the following well-known

dimensions.

- Relevance: is the initiative relevant to your target groups?

- Effectiveness: does the initiative cotribute to more fairness and improved economic, social, and environmental opportunities and benefits for your target groups?

- Continuity: can the initiative and its impact be sustained over time?

- Scale: does the initiative create opportunities that are scalable across all target groups?

The questions in step 4 have four answer options. They are:

- No: this is not the case/ we do not know

- Limited: this can happen occasionally / of rather poor quality

- Substantial: this is generally the case, but not always or as good as we would like to

- Yes: this is happening at the desired level

\section{Effectiveness}

Does the initiative...

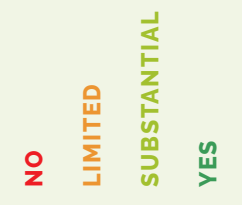

4. Contribute to a fair sharing of the benefits, costs, and risks among the stakeholders? (In terms of value distribution, trading practices, and employment contracts, etc.)

Considerations: Are your products/services targeting a very small niche of customers, or are they potential of more general interest?

5. Contribute to improved livelihoods and resilience? (In terms of income, assets,

food, access to basic services, to natural resources, etc.)

Considerations: Think about how your initiative helps your target group to act independently in response to possible changes in their circumstances.

6. Respect human rights ? (Such as workers' rights, freedom of movement, freedom

to possess goods, and right to food and shelter.)

Considerations: Think about universal rights as well as rights that might be specific to your country.
Notes

Notes

Notes 


\section{(2) Inclusive Trade Scan}

\section{Step 3, Impact: How are target groups affected by your initiative?}

Impacts refer to the opportunities and benefits for all groups involved in the

initiative - and in particular for the

target groups that are in need of greater

inclusivity. The impacts can be considered

in terms of the following well-known

dimensions.

- Relevance: is the initiative relevant to your target groups?

- Effectiveness: does the initiative cotribute

to more fairness and improved economic.

social, and environmental opportunities and

benefits for your target groups?

Continuity: can the initiative and its impact

be sustained over time?

- Scale: does the initiative create

opportunities that are scalable across all

target groups?

The questions in step 4 have four answer options. They are:

- No: this is not the case/ we do not know

- Limited: this can happen occasionally / of rather poor quality

- Substantial: this is generally the case, but not always or as good as we would like to

- Yes: this is happening at the desired level
Effectiveness (continued)

Does the initiative.

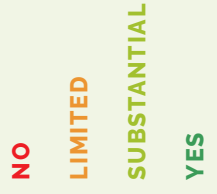

7. Contribute to the preservation or restoration of natural resources?

(Such as water, forest, soil,

biodiversity, and air.)

Considerations: Think of any aspect you have included as part of your goals or assumptions for your initiative.

Continuity

Does the initiative...

8. Build upon a viable business case? $\square \square \square$

Notes

Considerations: Will your initiative generate a realistic profit margin within a clear time frame based on market demand? If you need grants or subsidies to start up will you be able to phase them out?

9. Promote benefits that can be

$\square \square \square \square \quad$ Notes sustained?

Considerations: Considerations: are the outcomes one-off, or are they the result of a healthy business, part of structural agreements or embedded in policy and regulation?

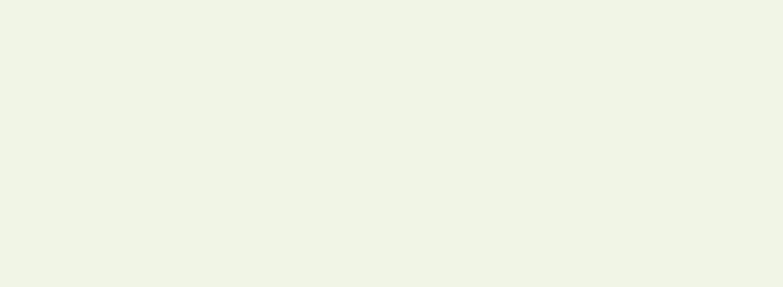




\section{(2) Inclusive Trade Scan}

\section{Step 3, Impact: How are target groups affected by your initiative?}

\section{Impacts refer to the opportunities and}

benefits for all groups involved in the

initiative - and in particular for the

target groups that are in need of greater

inclusivity. The impacts can be considered

in terms of the following well-known

dimensions.

- Relevance: is the initiative relevant to your target groups?

- Effectiveness: does the initiative cotribute

to more fairness and improved economic,

social, and environmental opportunities and

benefits for your target groups?

- Continuity: can the initiative and its impact

be sustained over time?

- Scale: does the initiative create

opportunities that are scalable across all

target groups?

The questions in step 4 have four answer options. They are:

- No: this is not the case/ we do not know

- Limited: this can happen occasionally / of rather poor quality

- Substantial: this is generally the case, but not always or as good as we would like to

- Yes: this is happening at the desired level

Scale

Does the initiative...

10. Promote opportunities which have the potential to be scaled?

Considerations: Are your products/services targeting a very small niche of customers, or are they potentially of more general interest?

11. Have a scaling strategy to grow the

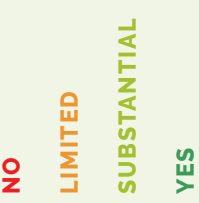

$\square \square \square \square \quad$ Notes impact?

Considerations: Have you considered what you will do after initial success? Will you consolidate what you have, will you seek to expand? And how you thought how you will expand your volumes/markets/inclusiveness in a deliberate manner? 


\section{(2) Inclusive Trade Scan}

\section{Step 4, Context: How does the context influence your inclusiveness?}

Before you start to think about how your initiative can become more inclusive, it is important to understand what your context is and how this influences your ability to be inclusive.

Here you can describe the context for each of the three levels and how it influences your ability to be inclusive at your level.

\section{Agribusiness}

Describe the nature of your target groups. Do they have the capacity, technical and financial resources, norms and attitudes to participate and benefit from your initiative? And what about the agribusiness(es) related to your initiative? Do they have the investment capacity. expertise and financial resiliency to be inclusive? What are market or climate dynamics which can influence the inclusiveness at this level?

\section{Value chain}

Describe the nature of trading relationships along the value chain which can influence inclusiveness Are trading relationships transparent, fair and stable? Do value chains support value creation and market responsiveness?

\section{Trade environment}

\section{A. Institutions and regulations}

Describe the way your sector is governed, both legally and informally. What policies and regulations are most helpful, which give most problems? What are relevant governing institutions and stakeholder platforms?

Is their sufficient public investment in for example research or quality management?

\section{b. Support services}

Describe the services needed for a more inclusive initiative (e.g. knowledge, technology, inputs, finance. infrastructure, market promotion). What is their availability, quality, affordability?

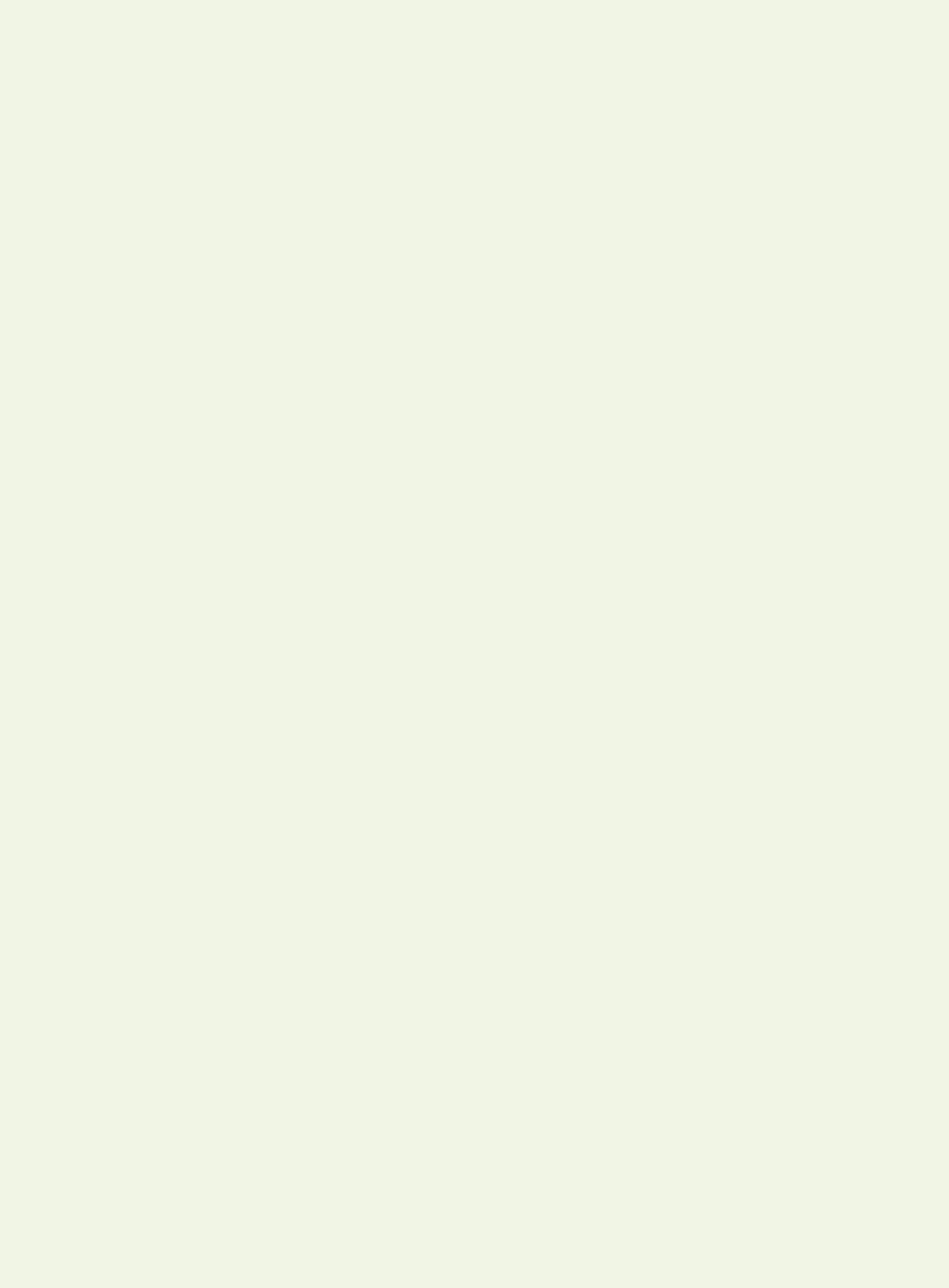




\section{Inclusive Trade Scan}

\section{Step 5, Priorities: What solutions are needed?}

Having filled in the questions in the previous steps, now is the time to use this to set your priorities for action.

$A$ and $B$ refer to the design of your initiative. $C$ and $D$ wil help you to prioritise actions that influence the context.

$\begin{array}{llll}\text { A. What are the most important gaps or } & \text { B. For each priority of improvement, what } & \text { C. For each priority of improvement, } & \begin{array}{l}\text { D. For each priority of contextual change, } \\ \text { biggest needs for improvement of your }\end{array} \\ \begin{array}{llll}\text { actions can you take within your initiative } \\ \text { initiative regarding the inclusiveness }\end{array} & \begin{array}{l}\text { to enhance the inclusiveness towards your } \\ \text { to enhance your ability to become more }\end{array} & \text { context (by yourself or in partnership)? }\end{array}$

initiative regarding the inclu

context (by yourself or in partnership)?

(see answers step $2 \& 3$ )

target groups?

inclusive? (see answers step 4)

A. Priorities for improvement

B. Priorities for direct action

C. Priorities for contextual change

D. Priorities for indirect action

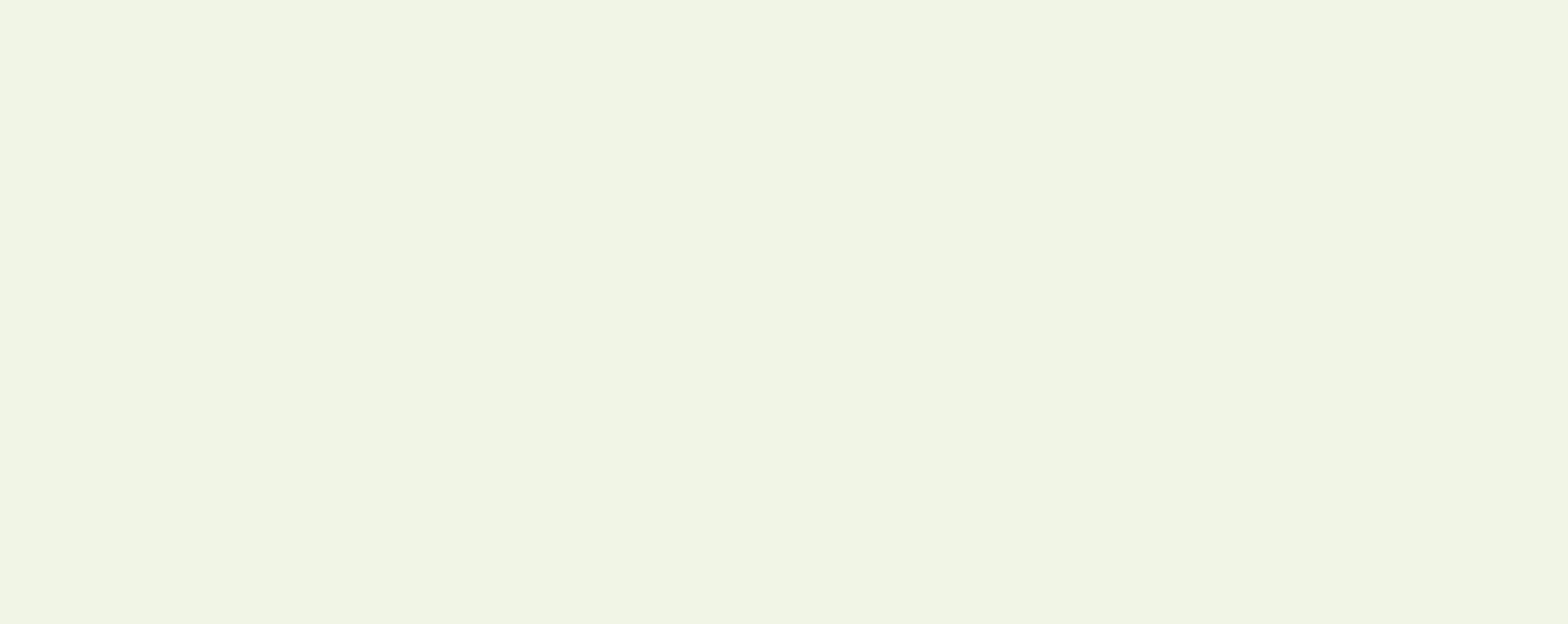


Once you have applied the Inclusive Trade Scan to your initiative, you will want to work with your findings. Here we suggest how you can design a process that increases the likelihood that the identified priority actions in step 5 will become reality.

\section{Develop a better understanding of your target groups and potential solutions}

You may need a better understanding of the needs of your target groups, the constraints and opportunities in the trade environment or the solutions which could make you become more inclusive. In such cases it is recommended to conduct further analysis le.g. target group consultation market research, policy analysis). In this analysis, make sure you engage directly with your target groups to avoid your findings will be based upon false assumptions. For the identification of solutions one can also search for lessons learned and best practices from peers and other similar initiatives.
Highlight inclusiveness in your goals and strategies

You can give inclusiveness a more prominent place in the goals of your initiative. This will push you to identify more inclusive engagement strategies, business models or policy frameworks. It will also help to communicate expectations around this within your organization and with other stakeholders.

\section{Embed inclusiveness in organizational structure and} processes

Objectives around inclusiveness can be embedded in your organization, for example by:

- Policies, embed inclusiveness aspects in hiring, gender or sourcing policies.

- Standard processes such as stakeholder consultation, due diligence processes, complaints and remedy mechanisms.

- Functions, by assigning inclusiveness relevant tasks and responsibilities to specific persons within your organization.

\section{Build internal skills}

One can invest in the capacity of your staff to better identify and address the needs of specific target groups.

\section{Build supportive partnerships}

One can look for like-minded partners that can support your initiative with expertise, networks and funding.

Partnerships are particularly useful when there is a need to influence the trade environment.

\section{Monitor progress}

You can regularly (e.g. annually) repeat the Inclusive Trade Scan in combination with additional monitoring activities to see the progress you have made and capture lessons that can help you to further improve your strategies 


\section{Relevant tools and resources}

Regarding stakeholder engagement:

UN Guiding Principles Reporting Framework

https://www.ungpreporting.org/

\section{Regarding agribusiness}

Blab Best Practice Guide: Diversity \& Inclusion in Your

Workplace:

http://go.pardot.com/l/39792/2018-05-22/8cp3ng

FAO Guiding principles for responsible contract farming operations:

http://wwww.fao.org/policy-support/tools-andpublications/resources-details/en/c/422951/

Seas of Change, Is inclusive business for you?:

https://seasofchange.net/is-inclusive-business-for-you/

WBCSD, Inclusive business:

https://wwww.wbcsd.org/Programs/People/Social-

Impact/Inclusive-Business/

Women empowerment in agriculture index:

https://www.ifpri.org/publication/womens-

empowerment-agriculture-index
Regarding value chains

IIED/Oxfam/Kent Business School/Unilever, Measuring

fairness in supply chain trading relationships: $A$

methodology guide:

https://pubs.iied.org/G03429/

Fairtrade Trader Standard:

https://www.fairtrade.net/standard/trader

LINK methodology: a participatory guide to business models that link smallholders to markets:

https://cgspace.cgiar.org/handle/10568/49606
Regarding trade environment

Springfield Markets for the Poor (M4P) approach:

https://www.springfieldcentre.com/who-we-are/our-

approach/

CFS, Principles for Responsible investment in agriculture and food systems:

http://wwww.fao.org/cfs/cfs-home/activities/rai/en/

Aidenvironment, IIED, Sustainable Food Lab: How can sector governance models drive sustainability performance

in smallholder-dominated agricultural sectors?:

https://sustainablefoodlab.org/wp-

contentuploads201705sector-governance-full-report_ may2017-pdf-2/

3R Kenya, Issue Briefs:

https://www.3r-kenya.org/cross-sectoral-publications/ 


\section{Colophon}

The Inclusive Business Scan was developed within the $3 R$ (robust, reliable resilient) - from 'Aid to Trade' project. This project draws lessons from the EKN Dutch Embassy programme in Agriculture and Food and Nutrition Security (FNS) with competitive agri-food sectors in Kenya. Development of the Inclusive Business Scan was funded by the EKN programme.

The Inclusive Trade Scan is part of efforts to make sure that 'inclusiveness' remains an actionable priority as trade-oriented investments grow

The Inclusive Trade Scan is a joint production between Wageningen Centre for Development Innovation and Aidenvironment.

\section{Reference:}

Guijt, J., J. W. Molenaar and M. Sopov (2021).

The Inclusive Trade Scan. Wageningen Centre for

Development Innovation, Wageningen. 24 pages.

DOI: https://doi.org/10.18174/541807

ISBN: 978-94-6395-715-1

\section{(cc) BY-NC}

Wageningen Centre for Development Innovation is part of Wageningen University \& Research. We work on processes of innovation and change through facilitating innovation, brokering knowledge and supporting capacity development.

https://wwww.wur.nl/en/Research-Results/ Research-Institutes/centre-for-developmentinnovation.htm
Layout: RCO.design

Photo's: Roger Reuver, Stephanie Malyon, Neil Palmer and Georgina Smith (CIAT)
WAGENINGEN

\section{aidenvironment}

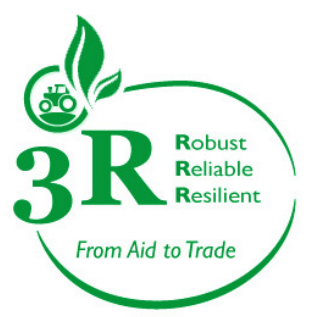

